\title{
Can biochar increase the bioavailability of phosphorus?
}

\author{
Q. Shen ${ }^{*}$, M. Hedley ${ }^{1}$, M. Camps Arbestain ${ }^{1}$, M.U.F. Kirschbaum²
}

${ }^{1}$ New Zealand Biochar Research Centre, Massey University, Private Bag 11222, Palmerston North 4442, New Zealand. ${ }^{2}$ Landcare Research, Private Bag 11052, Palmerston North 4442, New Zealand.

*Correspondin author: Q.shen@massey.ac.nz

\begin{abstract}
A large proportion of phosphate $(\mathrm{P})$ fertilizer applied to Andosols reacts with reactive aluminum (Al) and iron (Fe) to become unavailable for plant uptake. We investigated whether biochar could enhance plant growth by (i) mobilizing soil $\mathrm{P}$ through changing soil $\mathrm{pH}$ or facilitating the growth of arbuscular mycorrhizal fungi (AMF), and/or (ii) introducing additional $\mathrm{P}$.

We grew Lotus pedunculatus $c v$ barsille in two Andosols of contrasting P status amended with three biochars (with distinct porosity, nutrient and liming properties) at a dose of $10 \mathrm{t} \mathrm{ha}^{-1}$ for 32 weeks. The growth medium was divided into a root and a hyphal zone through a nylon mesh and a tephra layer that allowed the $\mathrm{P}$ in the hyphal zone to be transferred only by AMF hyphae.

The addition of a relative nutrient-rich biochar (e.g. made from willow woodchips) with liming properties to the root zone of the $\mathrm{P}$-deficient soil increased plant growth by $59 \%$ and $\mathrm{P}$ uptake by $73 \%$. Pine-based biochar provided no extra nutrient acquisition and no plant-growth stimulation when added to the root zone of the $\mathrm{P}$ deficient soil. However, when hyphae of those plants had access to a P-rich soil patch, the presence of pine biochar in the soil patch greatly enhanced $\mathrm{P}$ uptake and plant growth (e.g., by $76 \%$ and $40 \%$ when using biochar produced at $450{ }^{\circ} \mathrm{C}$ compared to the absence of it). None of the tested biochars conferred advantages in the root zone of a high-P soil.

We concluded that the benefits from biochar addition to nutrient uptake and plant growth are biochar- and soil-specific. Thus, biochars need to be tailored-made for certain soils by optimizing feedstock and pyrolysis conditions before application.
\end{abstract}

Keywords: Arbuscular mycorrhizal fungi, Andosols, Biochar, Lotus, Phosphorus bioavailability, Rhizosphere 


\section{Introduction}

Andosols are generally formed from volcanic parent materials at early stages of weathering, although they have also been identified in young soils developed from basic and metabasic rocks under humid and per-humid climates (IUSS Working Group 2006). These soils are characterized by having high content of short-range ordered constituents (e.g., allophane, imogolite, ferrihydrite), high organic matter content, low bulk density, good aeration, and adequate moisture retention (Dahlgren et al. 2004). Even though these distinctive properties make them suitable for agricultural use, the considerable presence of reactive $\mathrm{Al}$ (and to a lesser extent $\mathrm{Fe}$ ) surfaces generates a high affinity for $\mathrm{P}$, which commonly leads to low agronomic P use efficiency (IUSS Working Group 2006).

Two major reactions - adsorption and precipitation - are involved in the process of P fixation on these surfaces (Parfitt 1989). The former occurs mainly through ligand-exchange reactions (i.e., formation of inner-sphere complexes) of P-OH groups with exposed $-\mathrm{OH} / \mathrm{OH}_{2}$ groups in $\mathrm{Fe}$ and $\mathrm{Al}$ oxy-hydroxides and short-range ordered alumino silicates. Over time, after this initial adsorption, local solutes may become concentrated causing the precipitation of $\mathrm{Al} / \mathrm{Fe}$ phosphate, with some phosphate becoming occluded and isolated from solution. These reactions depend on soil $\mathrm{pH}$ and the saturation of surface binding sites with $\mathrm{P}$ (Goldberg and Sposito 1985).

In sil-andic Andosols - those with reactive Al being predominantly inorganic Al constituents (i.e. allophane) rather than organo-Al complexes - most of the non-available $\mathrm{P}$ is locked up with allophone (Parfitt 1989). This has led to an accumulation of up to almost 4 t $\mathrm{P} \mathrm{ha}^{-1}$ in intensively farmed sil-andic Andosols top-soils in New Zealand (Perrott and Sarathchandra 1987). Moreover, many sil-andic Andosols in New Zealand have been under (mainly legume- based) permanent pasture for a long time, which has led to soil acidification (Bolan and Hedley 2003; and references therein), which is likely to cause an increase in the positive charge of variable-charge constituents (e.g., reactive $\mathrm{Al}$ surfaces) and thus $\mathrm{P}$ sorption (Bolan et al. 1999).

Consequently, a relatively high input of $\mathrm{P}$ fertilizer is essential for maintaining pasture production in these soils. We used the nutrient budget model OVERSEER $^{(\mathrm{R})}$ version 6.1.2 to estimate fertilizer requirements for a typical dairy farm of sil-andic Andosols with a stocking rate of 2.8 cows ha ${ }^{-1}$ and a milk solids production of $980 \mathrm{~kg} \mathrm{ha}^{-1}$ in the Taranaki region (New Zealand). We found that the farm required $\mathrm{P}$ fertilization rates of up to $59 \mathrm{~kg} \mathrm{P} \mathrm{ha}^{-1}$ year $^{-1}$ to maintain a soil Olsen $P$ value of $35 \mathrm{mg} \mathrm{kg}^{-1}$ and sustain on going milk production at the set rate. Given that ongoing agricultural demand and diminishing mineable resources are expected to lead to a shortage of $\mathrm{P}$ (Cordell et al. 2009), it is necessary to consider management practices that can make the large pool of unavailable $\mathrm{P}$ in Andosols more available.

Biochar technology has thus been proposed as a $\mathrm{C}$ sequestration approach to contribute to the mitigation of greenhouse gas emissions (Lehmann et al. 2006). Additionally, purpose-made biochars hold promises in improving soil physical properties (Herath et al. 2013), reducing soil fertility constraints (Mia et al. 2014) and stimulating soil biological processes (Wang et al. 2015), and thereby enhance crop performance. Several studies have been undertaken to understand how P availability to plants can be directly or indirectly influenced by biochar addition and these are described below.

Certain biochars have liming properties and are thus likely to modify the soil $\mathrm{pH}$ (Curaqueo et al 2014), the extent of this effect being dependent on the $\mathrm{pH}-$ 
buffering capacity of both biochar and the soil (Yuan and $\mathrm{Xu}$ 2011). An increase in $\mathrm{pH}$ can reduce $\mathrm{P}$ adsorption and precipitation on reactive $\mathrm{Al}$ surfaces and also help overcome Al toxicity in acid soils (Haynes 1982). This, together with potential soil physical improvements following biochar incorporation, may provide plant roots with a better environment to grow and take up nutrients (Varela Milla et al 2013). The effect of biochar on $\mathrm{P}$ availability will also be influenced by the available P content of biochar (Wang et al. 2013). Furthermore, the addition of biochar may stimulate the activity of AMF (Warnock et al. 2007) by facilitating their abundance and functionality with the provision of a suitable environment through modifications of (i) soil pH (Solaiman et al. 2010), (ii) soil microporosity (Hammer et al. 2014), (iii) mineral nutrient availability (Hammer et al. 2014), and/or (iv) rootfungi signalling path [as suggested by Warnock et al. (2007) and Vanek and Lehmann (2014)]. Nonetheless, the magnitude of these effects will also depend on (i) biochar characteristics, (ii) biochar placement (e.g., distance from plant root), (iii) soil type, and (iv) soil P status [i.e., in a case study where biochar raised the soluble P supply in the soil, there was lower root AMF colonization than in non-amended soils (Vanek and Lehmann 2014)].

Although Vanek and Lehmann (2014) indicated that biochar enhanced the access of AMF to sparinglysoluble $\mathrm{P}$ in the rhizosphere, neither their study nor previous ones (to our knowledge), attempted to distinguish between the contribution of the roots and that of the AMF mycelium to P uptake, as influenced by the presence of biochar. Hence, the specific objectives of this study were to (i) investigate the effect of different biochars (all derived from wood, but with different nutrient contents, porosity, and liming properties) on soil $\mathrm{P}$ bioavailability when added to the root zone of two soils with contrasting P status; and (ii) examine whether the effect of biochar on AMF growth, if any, was dependent on its placement (e.g., in a P-rich soil patch within a low $\mathrm{P}$ soil). We hypothesize that: (i) a soil of high P status, either inherent of the soil or resulting from biochar addition, would discourage AMF mycelium branching; (ii) in a soil with low $\mathrm{P}$ availability, AMP hyphal growth would be stimulated to explore the soil at a further distance from the plant root in order to increase $\mathrm{P}$ supply; (iii) plant roots would play a more prominent role in $\mathrm{P}$ uptake over that of AMF hyphae when sufficient $\mathrm{P}$ was available in the system.

\section{Materials and Methods}

\subsection{Soil sampling and characterization}

Two Egmont black loam top soils (0-10 cm depth) - sil-andic Andosols (IUSS Working Group 2006)were collected from two sites $250 \mathrm{~m}$ apart in Mokoia, Taranaki, New Zealand. Both soils were characterized by having a high content of allophane $[>7 \%$, as estimated following the method of Mizota and Van Reeuwijk (1989)] derived from andesitic tephra. The two soils had strongly contrasting Olsen P levels; however, the high Olsen $\mathrm{P}$ soil $\left(33.3 \mathrm{mg} \mathrm{kg}^{-1}\right.$, referred to as 'HP') was sampled in an area of grazed permanent ryegrass/clover pasture (39 $37^{\prime} 11.30^{\prime}$ 'S, 17421'41.94'E), while the low Olsen P soil (4.3 mg $\mathrm{kg}^{-1}$, referred to as 'LP') was taken from an undisturbed area under rough pasture that had not received any fertilizer for the last 20 years (39 $37^{\prime} 18.02^{\prime}$ 'S, $174^{\circ} 21^{\prime} 38.73$ 'E). After removing roots and plant debris, fresh soil samples were sieved through a 2-mm sieve and stored in a cold room $\left(<4^{\circ} \mathrm{C}\right)$ for further use. Due to the typical micro-aggregation of allophonic soils, most of the soil passed through the sieve. Subsamples were taken, air-dried and characterized for chemical and physical properties (Table 1) using standard methods. 
Table 1. Selected properties of the two Andosols a

\begin{tabular}{|c|c|c|c|}
\hline Properties & Units & LP soil & HP soil \\
\hline Bulk density & $\mathrm{g} \mathrm{cm}^{-1}$ & 0.74 & 0.78 \\
\hline $\mathrm{pH}_{1: 2.5}$ & & 6.2 & 6.2 \\
\hline $\mathrm{pH}_{\mathrm{NaF}}$ & & 10.4 & 11.1 \\
\hline $\mathrm{CEC}^{\mathrm{b}}$ & $\operatorname{cmol}(+) \mathrm{kg}^{-1}$ & 13.5 & 13.9 \\
\hline$P$ retention capacity & $\%$ & 97 & 99 \\
\hline Olsen P & $\mathrm{mg} \mathrm{kg}^{-1}$ & 4.3 & 33.3 \\
\hline Resin-P & $\mathrm{mg} \mathrm{kg}^{-1}$ & 34 & 164 \\
\hline Total P & $\mathrm{mg} \mathrm{kg}^{-1}$ & 1981 & 4144 \\
\hline Total C & $\%$ & 8.0 & 10.6 \\
\hline$A 1_{p y}^{c}$ & $\%$ & 0.56 & 0.82 \\
\hline $\mathrm{Al}_{\mathrm{Ox}}{ }^{\mathrm{d}}$ & $\%$ & 2.50 & 3.16 \\
\hline $\mathrm{Al}_{\mathrm{ox}}+1 / 2 \mathrm{Fe}_{\mathrm{ox}}$ & $\%$ & 3.02 & 3.72 \\
\hline $\mathrm{A} 1_{\mathrm{py}} / \mathrm{Al}_{\mathrm{ox}}$ & & 0.23 & 0.26 \\
\hline Allophanecontent & $\%$ & 7.5 & 9.3 \\
\hline Exchangeable Al & $\mathrm{cmol} \mathrm{kg}^{-1}$ & 0.03 & 0.09 \\
\hline
\end{tabular}

${ }^{a} \mathrm{All}$ concentrations are expressed on an oven dry weight basis

${ }^{\mathrm{b} C a t i o n}$ exchangeable capacity

c Subscript pyreferred to sodium pyrophosphate-extractable

d Subscript ox referred to acid $(\mathrm{pH}=3)$ ammonium oxalate-extractable 
The soil $\mathrm{pH}_{1: 2.5}$ was determined using a glass electrode in a 1:2.5 soil: water suspension. The $\mathrm{pH}_{\mathrm{NaF}}$ at $\mathrm{t}=2$ min was measured in a 1:50 soil: saturated $\mathrm{NaF}$ suspension, a $\mathrm{pH}_{\mathrm{NaF}}>9.5$ indicates the presence of reactive $\mathrm{Al}$ (allophane and/or organo-Al complexes) (Fieldes and Perrott 1966). The CEC was determined by $1 \mathrm{M}$ ammonium acetate $(\mathrm{pH}=7)$ (Blakemore et al. 1987). Aluminium, $\mathrm{Fe}$ and $\mathrm{Si}$ from short-range ordered materials were extracted by acid ammonium oxalate $(\mathrm{pH}=3)\left(\mathrm{Al}_{\mathrm{ox}}, \mathrm{Fe}_{\text {ox }}\right.$ an$\mathrm{dSi}_{\mathrm{ox}}$ ) (Blakemore et al. 1987). Aluminium and Fe from organic complexes were extracted by sodium pyrophosphate $\left(\mathrm{Al}_{\mathrm{py}}\right.$ and $\left.\mathrm{Fe}_{\mathrm{py}}\right)$, although this reagent can also extract relatively small amounts from short-range ordered inorganic constituents (Blakemore et al. 1987). The exchangeable $\mathrm{Al}$ was extracted by $1 \mathrm{M} \mathrm{KCl}$ solution $\left(\mathrm{Al}_{\mathrm{ex}}\right.$ ) (Blakemore et al. 1987). The concentrations of $\mathrm{Al}, \mathrm{Fe}$ and $\mathrm{Si}$ in all extractants were determined by Atomic Absorption Spectroscopy (AAS, GBC 904 AvantaVer 1.33, Australia).

Total P was determined using a Technicon Auto-Analyzerafter Kjeldahl digestion. Olsen $\mathrm{P}$ was extracted by shaking $1 \mathrm{~g}$ of air-dried soil with $20 \mathrm{~mL}$ of $0.5 \mathrm{M}$ $\mathrm{NaHCO}_{3}$ solution $(\mathrm{pH}=8.5)$ for exactly $30 \mathrm{~min}(\mathrm{Ol}-$ sen et al. 1954). The suspension was then centrifuged at $25,155 \times g$ for $10 \mathrm{~min}$ and filtrated through Whatman No. 42 filter paper. Resin-P was extracted by adding $30 \mathrm{~mL}$ of deionized water and anion $\left(\mathrm{HCO}_{3}{ }^{-}\right.$ saturated) and cation $\left(\mathrm{Na}^{+}\right.$saturated) exchange resin strips $(6.25 * 2.5 \mathrm{~cm}$; BDH Chemicals Ltd., England (Saggar et al. 1990)) toca. $0.5 \mathrm{~g}$ soil sample; the suspension was shaken for $16 \mathrm{~h}$. Then the resin strips were transferred to a $0.5 \mathrm{M} \mathrm{NaCl}$ solution and shaken for $30 \mathrm{~min}$ (Wang et al. 2012a). The $\mathrm{P}$ in $\mathrm{NaHCO}_{3}(\mathrm{Olsen} \mathrm{P}$ ) and $\mathrm{NaCl}$ (Resin-P) solutions were then determined according to the ammonium molybdate (blue) method. Phosphorous retention capacity was determined by shaking $5 \mathrm{~g}$ of air-dried soil with $25 \mathrm{~mL}$ of $1000 \mathrm{mg} \mathrm{L}^{-1} \mathrm{P}$ solution as $\mathrm{KH}_{2} \mathrm{PO}_{4}$ (pre-dry at $105{ }^{\circ} \mathrm{C}$ for $1.5 \mathrm{~h}$ ) for $16 \mathrm{~h}$ (Saunders 1959); suspensions were centrifuged and filtrated as described above, and concentration of $\mathrm{P}$ in solution was then determined according to the vanadomolybdate (yellow) method.

\subsection{Biochar production and characterization}

Two types of feedstock were used for biochar production: (a) chipped pine (Pinus radiata D. Don) branches and (b) chipped weeping willow (Salix matsudana L.) branches. Pine wood chips were pyrolysedat $450{ }^{\circ} \mathrm{C}$ or $550{ }^{\circ} \mathrm{C}$ and willow wood chips only at $550{ }^{\circ} \mathrm{C}$ in a $27-\mathrm{L}$ gas-fired rotating drum kiln with an average heating rate of $10{ }^{\circ} \mathrm{C}$ $\mathrm{min}^{-1}$. The resultant solid pyrolytic products were referred to as BP450, BP550 and BW550, respectively. Biochars were ground to pass through a 2-mm sieve before mixing with soil for the bioassay trial. Subsamples were further ground to a particle size $<0.3 \mathrm{~mm}$ using a ring mill for characterization (Table 2). 
Table 2. Selected properties of biochars ${ }^{\mathrm{a}}$

\begin{tabular}{|c|c|c|c|c|}
\hline Biochar & Units & BP450 & BP550 & BW550 \\
\hline $\mathrm{pH}_{1: 20}$ & & 7.5 & 8.9 & 9.4 \\
\hline $\mathrm{EC}^{\mathrm{b}}$ & $\mu \mathrm{S} \mathrm{cm}^{-1}$ & 212 & 283 & 1165 \\
\hline Liming equivalence & $\% \mathrm{CaCO}_{3}$-eq & $\approx 0^{\mathrm{c}}$ & $\approx 0^{\mathrm{c}}$ & 18.2 \\
\hline Ash & $\%$ & 1.1 & 1.6 & 10.8 \\
\hline Total N & $\mathrm{g} \mathrm{kg}^{-1}$ & 3.5 & 4.8 & 17.8 \\
\hline Available $\mathrm{N}^{\mathrm{d}}$ & $\mathrm{mg} \mathrm{kg}^{-1}$ & 56.5 & 41.3 & 383.5 \\
\hline Total P & $\mathrm{mg} \mathrm{kg}^{-1}$ & 443 & 490 & 4234 \\
\hline Available $\mathrm{P}^{\mathrm{e}}$ & $\mathrm{mg} \mathrm{kg}^{-1}$ & 92 & 97 & 1588 \\
\hline Available $\mathrm{K}^{\mathrm{f}}$ & $\mathrm{g} \mathrm{kg}^{-1}$ & 3.59 & 4.60 & 12.84 \\
\hline Available $\mathrm{Mg}^{\mathrm{g}}$ & $\mathrm{g} \mathrm{kg}^{-1}$ & 0.38 & 0.21 & 2.95 \\
\hline Available $\mathrm{S}^{\mathrm{h}}$ & $\mathrm{mg} \mathrm{kg}^{-1}$ & 69 & 59 & 2606 \\
\hline Resin-P & $\mathrm{mg} \mathrm{kg}^{-1}$ & 69 & 61 & 268 \\
\hline
\end{tabular}

${ }^{a}$ All concentrations are expressed on an oven dry weight basis

bElectrical conductivity

$c<$ Detection limit

d $6 \mathrm{M} \mathrm{HCl}$ hydrolysable $\mathrm{N}$

e $2 \%$ formic acid extractable $P$

f, g, h 1 N HCl-extractable K, Mg, S 
The $\mathrm{pH}$ and EC were measured in a suspension of biochar in deionized water (ratio of 1:20; w/w), as suggested by the IBI (2012). Calcium carbonate equivalence (liming equivalence, $\% \mathrm{CaCO}_{3}$-eq) was determined following a modified version of the method proposed by Rayment and Higginson (1992). For this, $10 \mathrm{~mL}$ of $1 \mathrm{M} \mathrm{HCl}$ solution (standardized) was added to $0.5 \mathrm{~g}$ of biochar. The suspension was then shaken on an end-to-end shaker for $2 \mathrm{~h}$ and stood overnight. The excess $\mathrm{HCl}$ in the suspension without any separation was then titrated against $1 \mathrm{M} \mathrm{NaOH}$ solution (standardized) under vigorous stirring using an autotitrator (TIM 865 Titration Manager, Radiometer Analytical).

A available $\mathrm{P}$ ( $2 \%$ formic acid extractable $\mathrm{P})$ and $\mathrm{N}$ (6 $\mathrm{M} \mathrm{HCl}$ hydrolysable $\mathrm{N}$ ) were measured according to the methodologies of Wang et al. (2012a, b), respectively. Available $\mathrm{K}, \mathrm{S}$ and $\mathrm{Mg}$ were determined following the method recommended by CampsArbestain et al. (2015). In brief, $10 \mathrm{~mL}$ of $1 \mathrm{M} \mathrm{HCl}$ solution was added to $0.5 \mathrm{~g}$ of biochar. The suspension was then shaken on an end-to-end shaker for 2 $\mathrm{h}$ and stood overnight. The suspension was thereafter filtered through Whatman No 42 filter paper. Potassium and $\mathrm{Mg}$, and $\mathrm{S}$ in the extractants were determined using Atomic Absorption Spectroscopy (AAS, GBC 904 AvantaVer 1.33, Australia) and a $\mathrm{SO}_{4}-\mathrm{S}$ Technicon Auto-Analyzer, respectively. Total C, H, N and $\mathrm{S}$ contents were determined using a TruSpec CHNS analyzer (LECO Corp. St. Joseph, MI). The ash content was determined by thermal analysis using a TG analyzer (SDT Q600, TA Instruments, Melbourne, Australia).

\subsection{Ioassay experiment setup}

Lotus pedunculatus cv barsille was grown in a root study container that separated the soil into root and hyphalzones. This allowed a distinction to be made between direct $\mathrm{P}$ uptake by plant roots and uptake through transfer by AMF hyphae (Figure 1a). Plant roots could access only the upper soil compartment (the root zone). It was separated from the lower compartment by a 30$\mu \mathrm{m}$ root exclusion nylon mesh that prevented root penetration but allowed unhindered penetration by thinner hyphae. A thin layer (3-mm) of high P sorbing tephra was placed below the root exclusion mesh to provide a 'P-diffusion break' to ensure that $\mathrm{P}$ could not enter the root zone by passive diffusion, either. The two different soil compartments could then be filled with soil with different $\mathrm{P}$ concentrations, and with or without adding biochar to observe $\mathrm{P}$ uptake and plant growth under differing $\mathrm{P}$ status, and the influence of biochar on either root or hyphal $\mathrm{P}$ uptake.

The root study containers were packed with soils and/ or soil-biochar mixtures according to the experimental design:

$\frac{L O}{L O}, \frac{L B}{L O}, \frac{H O}{L O}, \frac{H B}{L O}, \frac{L O}{H O}, \frac{L B}{H O}, \frac{L B}{H B}\left(\frac{\text { upper compartment }}{\text { lower compartment }}\right.$ $\mathrm{L}=\mathrm{LP}$ soil, $\mathrm{H}=\mathrm{HP}$ soil, $\mathrm{B}=$ with biochar and $\mathrm{O}=$ without biochar) (Figure 1b). Biochar was added to the soils at a rate of $4.5 \%(\mathrm{w} / \mathrm{w}$, which was equivalent to a field deep-banded rate of $10 \mathrm{tha}^{-1}$, assuming a fertilizer band of $25 \mathrm{~cm}$ within a row of $80 \mathrm{~cm}$ ). Four replicates of each treatment were established and preincubated at a soil volumetric water content of $70 \%$ of field water holding capacity for 2 weeks (time 0 ). 


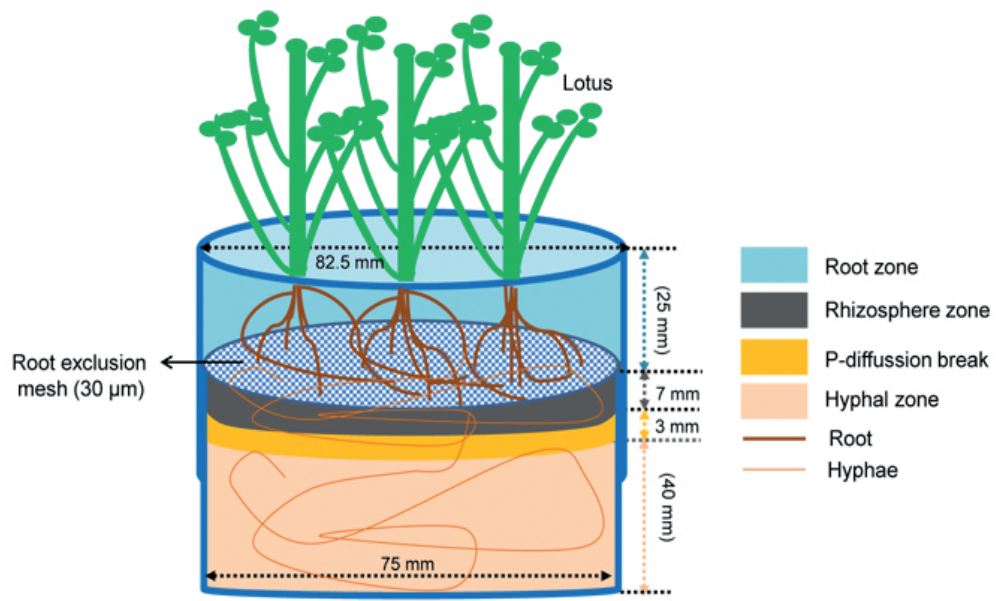

b.
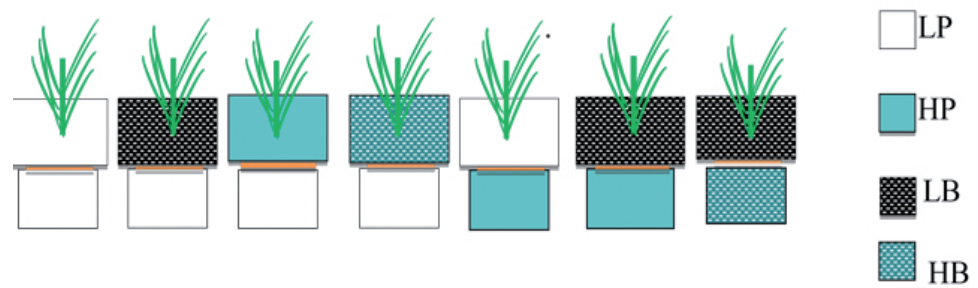

$\frac{\mathrm{LO}}{\mathrm{LO}} \quad \frac{\mathrm{LB}}{\mathrm{LO}} \quad \frac{\mathrm{HO}}{\mathrm{LO}} \quad \frac{\mathrm{HB}}{\mathrm{LO}} \quad \frac{\mathrm{LO}}{\mathrm{HO}} \quad \frac{\mathrm{LB}}{\mathrm{HO}} \quad \frac{\mathrm{LB}}{\mathrm{HB}}$

Figure 1. Schematic representation of the root study containers (a) and experimental treatments (b)

\subsection{Plant growth and harvesting}

Thirty seeds of Lotus pedunculatus cv barsille (inoculated with Rhizobium) were sown per root study container after 2 weeks of pre-incubation. Visual inspection identified abundant indigenous AMF so that no external inoculum needed to be introduced. Two weeks after germination, the seedlings were thinned to five plants per pot. All pots were arranged in a completely-randomized design and kept in a glasshouse.
Natural light was supplemented by four growth lights (F58W-GRO-LUX, $1500 \mathrm{~mm} * 26 \mathrm{~mm}$ ) to provide 16 $\mathrm{h}$ of light per day. An N- and P-free nutrient solution was applied regularly to maintain plant growth. Visual inspection showed that Rhizobium nodules had developed adequately and maintained adequate $\mathrm{N}$ supply to plants. This ensured that $\mathrm{P}$ was the principal element limiting plant growth. Water content was maintained at $70 \%$ of field water holding capacity throughout the trial period by weighing the pots daily and adding water to reach the corresponding weight. 
Plants were harvested on four occasions when the height of most plants reached $15 \mathrm{~cm}$. For this, the aboveground biomass was cut down to $2-3 \mathrm{~cm}$ above the soil surface, then dried at $75^{\circ} \mathrm{C}$ to constant weight and weighed to determine the aboveground DM. Subsamples were ground using a ball mill and analyzed for shoot P concentration on a TechniconAuto-Analyzer after Kjeldahl digestion.

After 32 weeks, a final harvest was carried out and the root study containers were destructively separated. The rhizosphere soil (directly under the mesh) was sliced using a piston microtome starting at a $0.5 \mathrm{~mm}$ thickness to sample pure tephra from the 3-mm tephra layer for $\mathrm{P}$ analysis to test the success of using tephra as a $\mathrm{P}$ diffusion barrier. Another set of six slices of the hyphal zone soil (Figure 1a) were taken each at $1 \mathrm{~mm}$ thickness. All slices were kept separately and stored in a chilled room $\left(<4^{\circ} \mathrm{C}\right)$ for further analysis. The root zone soil was carefully removed from the upper compartment and sliced into eight wedges; four of those were randomly selected, then crushed and passed thought a 2-mm sieve. Big roots remaining in the sieves were separated and the soil was air-dried for further analysis.

\subsection{Measurement of hyphal length}

Hyphae present in the hyphal zone soil (a $1 \mathrm{~mm}$ thick soil right below the tephra) were extracted, stained and measured using a photomicrography - image processing using the Image J software (1.47 bundled with 64-bit Java, http://imagej.nih.gov/ij/) following the method described and tested by Shen et al. (2016).

\subsection{Statistical analysis}

Unless other wise stated, results are expressed as means of four replicates with their standard errors. One-way ANOVA with a Tukey post-hoc test was used to evaluate statistical differences $(P=0.05)$ in plant dry matter (DM) and $\mathrm{P}$ uptake between treatments by SPSS software (IBM SPSS Statistics 20). Linear regression models were used to test for correlation among plant yield and soil $\mathrm{pH}$ responses.

\section{Results}

\subsection{Biochar characteristics}

The chemical characterization of the investigated biochars showed that, under the conditions studied, the types of feedstock had a greater effect on their properties than pyrolysis temperature (Table 2). The ash content of the willow woodchip-derived biochar (BW550) was more than six times as high as that of the two pine-based biochars $(>10 v s .<2 \%)$. This, along with its composition, played an important role in several properties of biochar. The BW550 biochar had values of $\mathrm{pH}, \mathrm{EC}$ and liming equivalence of 9.4, $1165 \mu \mathrm{cm}^{-1}$ and $18.2 \% \mathrm{CaCO}_{3}$-eq, respectively. The corresponding $\mathrm{pH}$ and $\mathrm{EC}$ values for the BP450 and BP550 biochars were $<9$ and $<300 \mu S \mathrm{~cm}^{-1}$, respectively, with no detectable $\mathrm{CaCO}_{3}$-eqin either of them. Total P and available P in the BW550 biochar was > 8 and $>17$ times higher than the corresponding values in the BP450 and BP550 biochars. The available $\mathrm{K}, \mathrm{Mg}$ and $\mathrm{S}$ in the BW550 biochar were $>3,>8$ and $>38$ times higher than the corresponding values in the biochar derived from pine woodchips.

\subsection{P status and biochar effects in the root zone}

The inferior growth of plants in the LP soil compared to the HP soil (3.4 vs. $9.5 \mathrm{~g} \mathrm{pot}^{-1}$ of shoot DM, respectively, Figure 2A) along with correspondingly lower P uptake by plant shoots $\left(2.0\right.$ vs. $9.0 \mathrm{~g} \mathrm{pot}^{-1}$, respectively, Figure 2B) and lower P concentration in shoots ( $0.06 \%$ vs. $0.1 \%$, data not shown), confirmed the $\mathrm{P}$ 
limitation of the LP soil and its poor ability to provide root zone-derived P. The addition of the BW550 biochar to the LP soil (treatment $\frac{\mathrm{LB}}{\mathrm{LO}}$ ) partly alleviated this deficiency with a significant increase in plant growth (by $58 \% ; P<0.01$ ) and $\mathrm{P}$ uptake (by $73 \% ; P<0.05$ ) (Figure 2A). However, this increase was always below that obtained by plants with roots growing the HP soil $\left(\frac{\mathrm{HO}}{\mathrm{LO}}\right)$ : these had increases $(P<0.05)$ by $180 \%$ and $343 \%$, respectively, compared with the LP soil $\left(\frac{10}{\llcorner 0}\right)$. The addition of the same biochar to the root zone of the HP soil ( $\left(\frac{\mathrm{HB}}{\mathrm{LO}}\right)$ had no significant $(P>0.05)$ effect on either plant growth or P uptake (Figure 2). When pine-derived biochars (BP450 and BP550) were added to the root zone of either the LP soil or the HP soil, neither of them had a significant effect on either plant yield or P uptake (Figure 2).
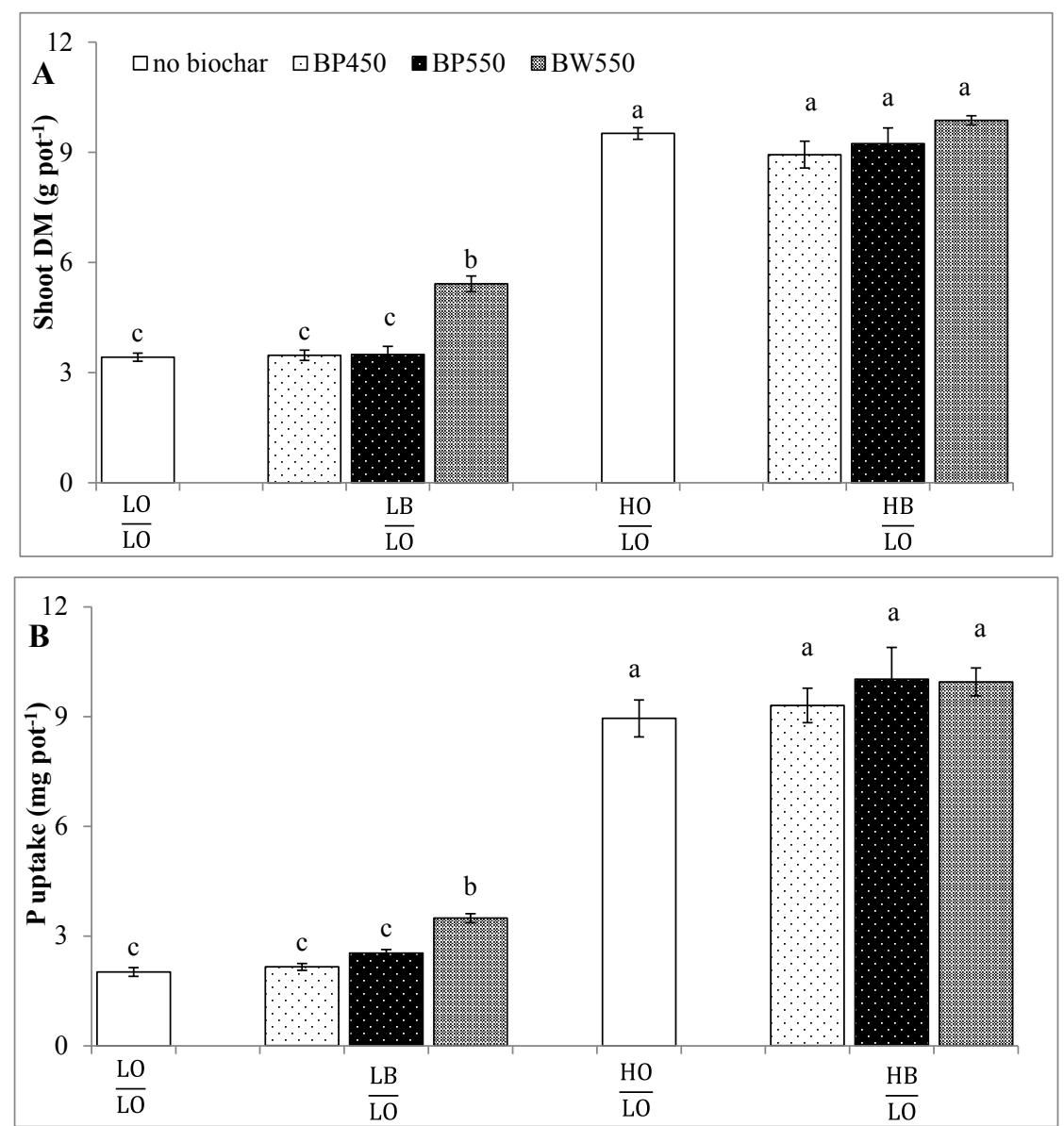

Figure 2. Effect of the P status in the root zone soil and biochar on plant growth (shoot DM) (A) and P uptake (B). The data present was the sum of four harvests. The error bars denote 1 SE. Different letters indicate significant differences $(P<0.05, \mathrm{n}=4)$ as determined by one-way ANOVA 


\subsection{P status and biochar effects in the hyphal zone}

Phosphorus (total $\mathrm{P}$ and $\mathrm{P}$ fractionation) measurements in pure tephra slices showed that $\mathrm{P}$ could not have diffused from the HP soil - present in the hyphal zone-to the root zone (Shen et al., unpublished). Given that roots could not penetrate to the hyphal zone to take up Peither, P uptake by plant from the hyphal zone of HP soil was only possible through indirect uptake by AMF hyphae. The growth analysis confirmed that plants grew faster $(P<0.05)$ when their hyphae could access P from the HP soil in their hyphal zone. Plants P uptake was increased by $94 \%$ and resulted in a $56 \%$ increase in above-ground DM when plants were growing in the $\frac{L 0}{1 \% 0}$ treatment compared to in the ț treatment (Figure 3).
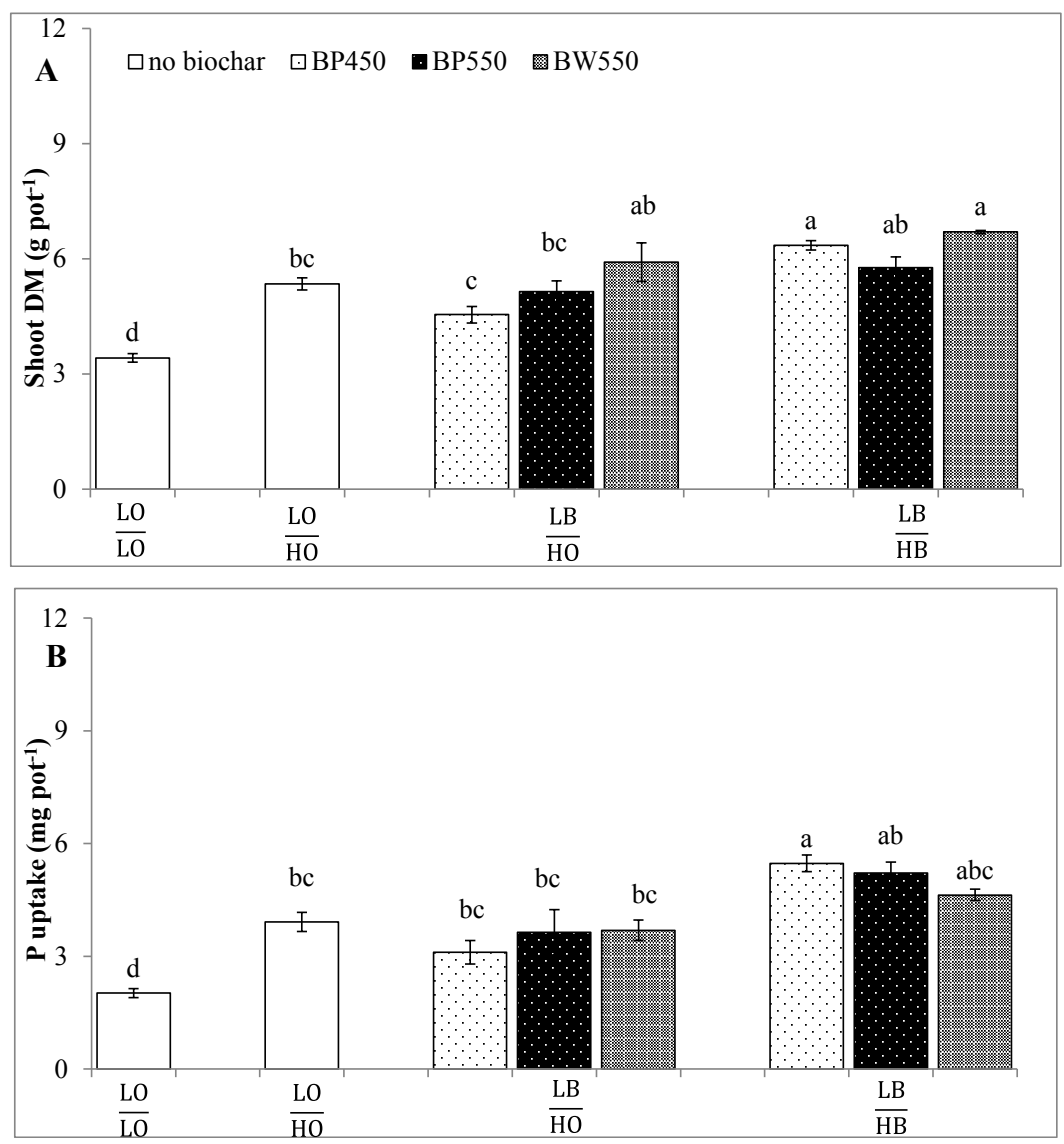

Figure 3. Effect of the presence of the HP soil (to which only hyphae had access) below the root zone of LP soil - with and without biochar - on plant growth (shoot DM) (A) and P uptake (B). The data present was the sum of four harvests. The error bars denote $1 \mathrm{SE}$. Different letters indicate significant differences $(P<0.05, \mathrm{n}=4)$ as determined by one-way ANOVA 
The addition of biochar BW550 to the root zone of the $\frac{\mathrm{LO}}{\mathrm{HO}}$ combination (resulting in treatment) caused an increase in plant shoot DM, but this effect was not significant $(P>0.05)$, as neither was the addition of pine biochar (Figure 3). When the biochar was also added to the $h y$ phal zone of the HP soil (treatment $\frac{\mathrm{LB}}{\mathrm{HB}}$ ), the pots amended with BP450 had anincrease $(P<0.05)$ in shoot DM yield and $\mathrm{P}$ uptake (by 40 and $76 \%$, respectively) compared to the treatment with biochar only added to the root zone of LP soil (treatment $\frac{\mathrm{LB}}{\mathrm{HO}}$ ). Growth and P uptake were also increased in pots with the hyphal zones amended with other biochars, although effects were not significant $(P>0.05)$.

In general, $\mathrm{P}$ uptake by plants was more sensitive to the types and the placements (to either root zone or hyphal zone soil) of biochar than biomass growth (Figure 4). Phosphate uptake differed almost five-fold between plants grown with low-P and high-P soils in their root zones, whereas growth differed less than three-fold. Plant $\mathrm{P}$ uptake and growth could be increased by about $50 \%$ when BW550 was added to the root zone, presumably as an alternative means of supplying the required $\mathrm{P}$ directly to roots. Alternatively, a similar enhancement of $\mathrm{P}$ uptake and growth was possible through hyphal $\mathrm{P}$ uptake when hyphae could grow in the hyphal zone of a high-P, and that benefit could be even further enhanced when biochar was added to high-P soils within the hyphal zone, with similar benefits for the three different biochar types. In contrast, there was little effect when any of the biochars was added to high-P root zones (Figure 4)
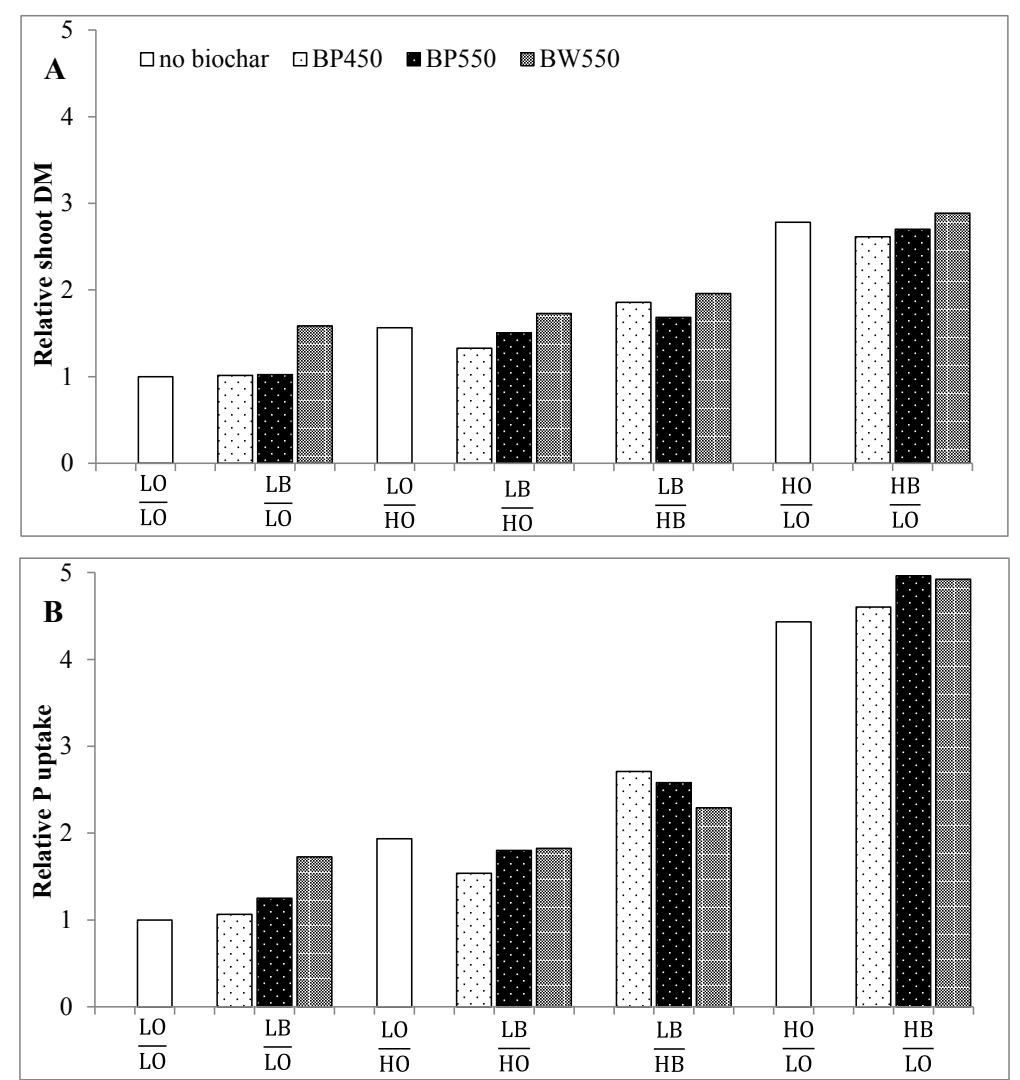

Figure 4. The relative plant shoot DM (A) and P uptake (B) were expressed relative to the shoot DM and P uptake of plants grown in the treatment without any amendments. 


\subsection{Effects of biochar on available $P$ and $p H$ of the root zone soil}

The presence of BW550 biochar increased $(P<0.01)$ the Resin-P in both the HP and the LP soils at time 0 (after 2 weeks pre-incubation but before sowing) (Figure 5A). BW550 biochar had a higher available $\mathrm{P}$ than the BP450 and BP550 biochars (Table 2), and thus made a greater contribution to available $\mathrm{P}$ in both soils (Figure 5A). Conversely, neither BP450 nor BP550 had any discernible effects on the plant available $\mathrm{P}$ fraction in the LP soil, as expected, but their application resulted in a reduction $(P<0.05)$ in plant available $\mathrm{P}$ when applied to the HP soil. It is likely that this was simply due to the dilution of available $\mathrm{P}$ when pine biochars with very low available $\mathrm{P}$ (ResinP) concentrations (59 and $69 \mathrm{mg} \mathrm{kg}^{-1}$; Table 2) was added to the HP soil with a very high available $\mathrm{P}$ concentration).

After 8 months of plant growth, the Resin-P in the root zone (Figure 5A) decreased $(P<0.05)$ in all treatments over the period of plant growth, except for the LP soil amended with BW550. Generally, this decrease was greater in the HP soil than in LP soil (> 80 vs. $>10 \mathrm{mg} \mathrm{kg}^{-1}$, respectively) due to greater plant $\mathrm{P}$ uptake in the former. However, the Resin-P in soils amended with the BW550 biochar was still higher $(P<0.05)$ (in general $\left.c a .10 \mathrm{mg} \mathrm{kg}^{-1}\right)$ than those of the non-amended and pine biochar-amended counterparts (Figure 5A).

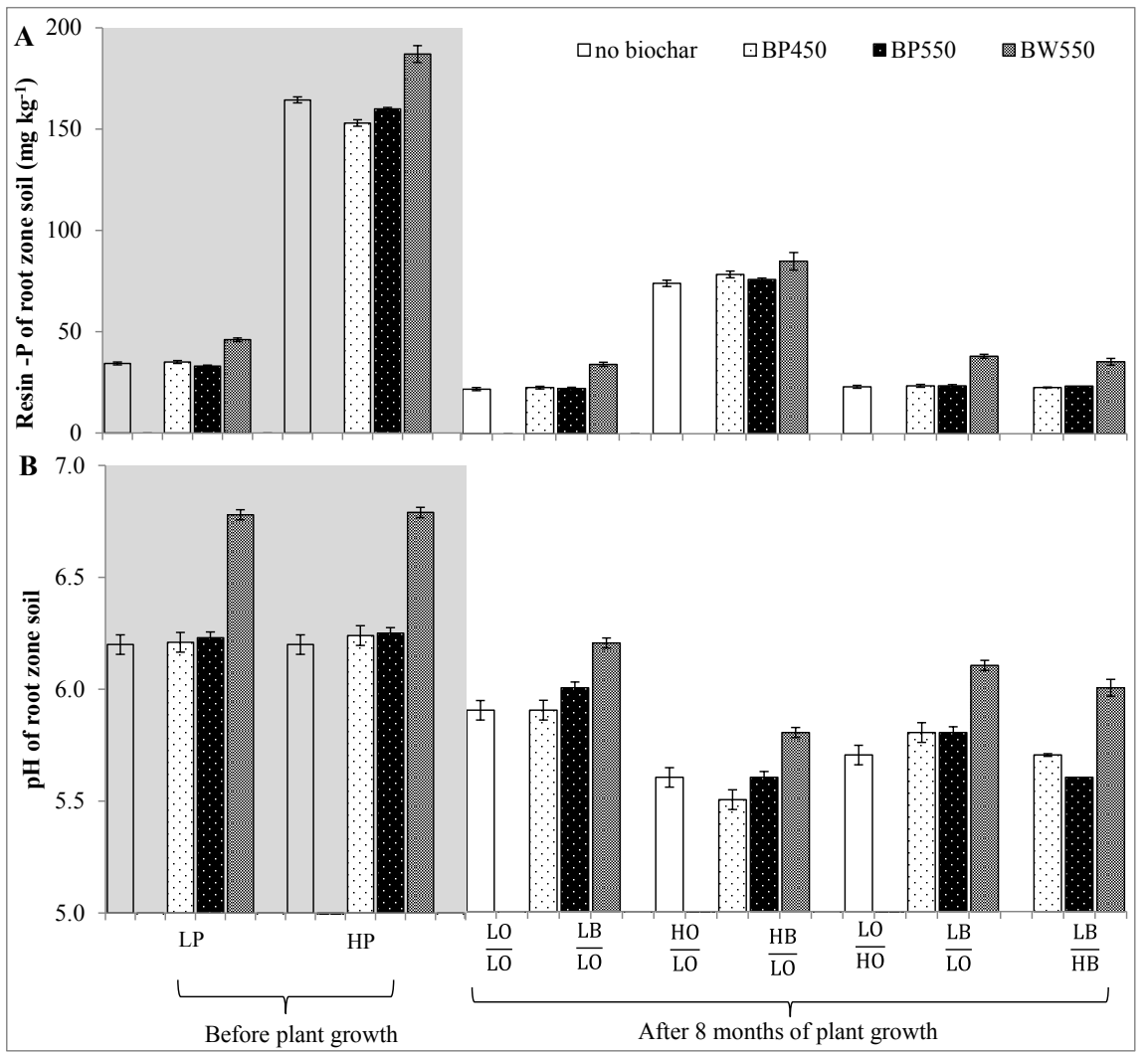

Figure 5. Effect of biochar on Resin - P (A) and pH (B) of the root zone soil after plant growth 
Over the course of the experiment, soil $\mathrm{pH}$ in the root zone of non-amended pots also decreased by $0.3-0.5$ units in the LP soil and 0.6 units in HP soil, respectively (Figure 5B). A similar pattern of $\mathrm{pH}$ change was observed when pine wood biochars were added to these soils, but the soil amended with BW550 biochar when compared to the soil without any amendments, had less of a decrease in $\mathrm{pH}$. However, when compared to the soil amended with BW550 at time 0, the decrease $\mathrm{pH}$ was actually more pronounced (0.6-0.8). Overall, the decrease of soil $\mathrm{pH}$ in the root zone was correlated $\left(\mathrm{R}^{2}=0.68\right)$ with the above-ground biomass growth (Figure 6).

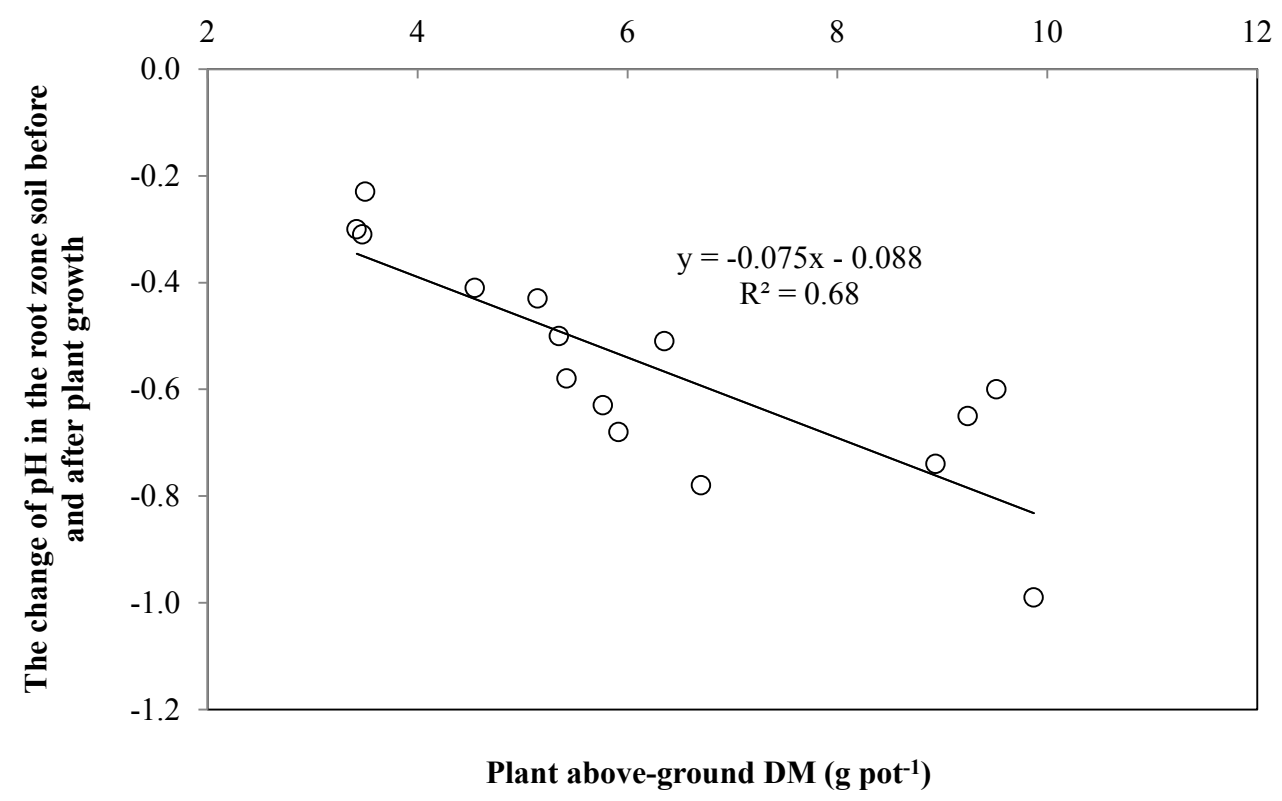

Figure 6. Correlation between plant growth and decrease of soil $\mathrm{pH}$

\subsection{Effects of soil type and biochar type on AMF} abundance in the hyphal zone

In the non-biochar treatments, hyphal lengths in the hyphal zone increased $(P<0.05)$ with decreasing available $\mathrm{P}$ in the soil and plant shoot DM: treatment $\left(4.4 \mathrm{~m} \mathrm{~g}^{-1}\right.$ soil g $\left.{ }^{-1} \mathrm{DM}\right)>$ treatment $\left(1.9 \mathrm{~m} \mathrm{~g}^{-1}\right.$ soil $\left.\mathrm{g}^{-1} \mathrm{DM}\right)>$ treatment $\left(0.7 \mathrm{~m} \mathrm{~g}^{-1}\right.$ soil g $\left.\mathrm{g}^{-1} \mathrm{DM}\right)$ (Table 3). Compared to a hyphal length of $1.9 \mathrm{~m} \mathrm{~g}^{-1}$ soil $\mathrm{g}^{-1} \mathrm{DM}$ in treatment, the application of BP450 biochar increased $(P<0.05)$ AMF hyphae length in the hyphal zone reaching values $>2.6 \mathrm{~m} \mathrm{~g}^{-1}$ soil g-1 DM. The incorporation of BP550 biochar marginally increased ( $P>0.05$ ) hyphal length (to $2.3-2.4 \mathrm{~m} \mathrm{~g}^{-1}$ soil $\left.\mathrm{g}^{-1} \mathrm{DM}\right)$. Conversely, a marginal decrease in hyphal length in the hyphal zone was detected when BW550 was added with respect to the non-amended counterpart (1.5-1.6 vs. $1.9 \mathrm{~m} \mathrm{~g}^{-1}$ soil g $\left.\mathrm{g}^{-1} \mathrm{DM}\right)$ 
Table 3. AMF hyphal lengths in the hyphal zone soil below the tephra layer (a $1 \mathrm{~mm}$ thick soil right below the

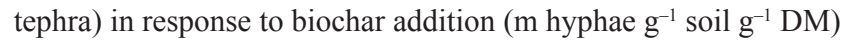

\begin{tabular}{|c|c|c|c|c|c|c|c|c|}
\hline \multirow{3}{*}{$\frac{\mathrm{LO}}{\mathrm{LO}}$} & $\mathrm{HO}$ & LO & \multicolumn{3}{|c|}{ LB } & \multicolumn{3}{|c|}{ LB } \\
\hline & $\overline{\mathrm{LO}}$ & $\overline{\mathrm{HO}}$ & & $\overline{\mathrm{HO}}$ & & & $\overline{\mathrm{HB}}$ & \\
\hline & & & BP450 & BP550 & BW550 & BP450 & BP550 & BW550 \\
\hline $4.4 \mathrm{a}$ & $0.7 \mathrm{~d}$ & $1.9 \mathrm{c}$ & $2.6 \mathrm{~b}$ & $2.3 b c$ & $1.5 \mathrm{c}$ & $2.7 \mathrm{~b}$ & $2.4 \mathrm{bc}$ & $1.6 \mathrm{c}$ \\
\hline
\end{tabular}

*Different letters within each row indicate significant differences $(P<0.05, \mathrm{n}=4)$ as determined by one-way ANOVA

\section{Discussion}

\subsection{Biochar classification}

According to the biochar classification system of CampsArbestain et al. (2015) the BP450, BP550 and BW550 biochars were classified as follows: (i) fertilizer values based on an 'average' corn grain crop with a yield of $13 \mathrm{t}$ $\mathrm{DM} \mathrm{ha}^{-1} \mathrm{y}^{-1}$ (classes $0 ; 0 ; 3, \mathrm{~K}_{5 \mathrm{t}} \mathrm{S}_{6 \mathrm{t}} \mathrm{Mg}_{7 \mathrm{t}}$, respectively) and (ii) liming equivalence value (classes $0 ; 0 ; 2$, respectively). The results thus indicate BW550 biochar would provide an adequate supply of $\mathrm{K}, \mathrm{S}$ and $\mathrm{Mg}$ to an 'average' corn crop at doses of 5, 6 and $7 \mathrm{tha}^{-1}$, respectively. The nutrient requirement of an 'average' lotus crop yield of 11.5 t DM ha ${ }^{-1} \mathrm{y}^{-1}$ (Suckling 1960) would need a biochar application of $7 \mathrm{tha}^{-1}$ to supply sufficient $\mathrm{S}$ and $\mathrm{Mg}$, and $20 \mathrm{tha}^{-1}$ to meet the requirements for $\mathrm{P}$ and $\mathrm{K}$. Moreover, the relatively high liming equivalence of the BW550 biochar $\left(18.2 \% \mathrm{CaCO}_{3}\right.$-eq) means that this biochar would also alleviate soil acidity and $\mathrm{Al}$ toxicity.

\subsection{P status of soil and biochar in the root zone affects plant growth and $P$ uptake}

The plants grown in the LP root zone soil (without biochar amendment) suffered from $\mathrm{P}$ deficiency as inferred from the inferior growth and lower P uptake by plant shoots compared to those grown in the HP root zone soil. Shoot $\mathrm{P}$ concentrations of plants grown in the LP $(0.06 \%)$ and HP soils $(0.10 \%)$ were below those commonly reported for lotus $(0.15-0.25 \%)$ (Trolove et al. 1996). However, this comparison is misled by the fact that plant growth under glasshouse conditions $\left(9.5 \mathrm{~g} \mathrm{pot}^{-1}\right.$ in a growth period of 8 months would be equivalent to $27 \mathrm{t} \mathrm{DM} \mathrm{ha}^{-1} \mathrm{y}^{-1}$ ) was more than 2.5-fold that under field conditions (11.5 t DM $\mathrm{ha}^{-1} \mathrm{y}^{-1}$; Suckling 1960), which caused a dilution effect in shoot $\mathrm{P}$ concentration.

The incorporation of BW550 biochar into the LP root zone soil caused a considerable increase in $\mathrm{P}$ uptake and a concomitant increase in plant yield compared to the non-amended soil. A similar growth enhancement was not observed in the corresponding treatments amended with the pine-based biochars. This difference in response to biochar types was attributed to the additional nutrients provided by the BW550 that was rich in ash and, particularly, its input of available $\mathrm{P}$ to this P-deficient soil. The addition of BW550 biochar to the LP soil increased Resin-P by $12 \mathrm{mg} \mathrm{kg}^{-1}$ (Figure 5A). Assuming that the difference in $\mathrm{P}$ taken up by plants with and without BW550 biochar came from the $\mathrm{P}$ contained in the biochar, we estimated that 
ca. $20 \%$ of the additional available $\mathrm{P}$ introduced by BW550 biochar was taken up by plants. Resin-P has been proposed as a potentially useful test for characterizing P bioavailability in soils amended with P-rich biochars (Wang et al. 2012a).

BW550 biochar also increased the pH-buffering capacity of these soils and helped mitigate the decrease in $\mathrm{pH}$ experienced over time which may have also favoured $\mathrm{P}$ uptake. The decrease in $\mathrm{pH}$ was always greater in the HP soil than in the LP soil, and this could be attributed to the greater root growth and DM accumulation observed in the HP soil, although there may have also been differences in soil $\mathrm{pH}$-buffering capacities between the two soils. Plant-P availability is affected by several $\mathrm{pH}$-dependent reactions such as $\mathrm{P}$ speciation, precipitation-dissolution and adsorption-desorption. An increase in soil $\mathrm{pH}$ generally favours $\mathrm{P}$ mobilization and could also stimulate the mineralization of organic P (Haynes 1982).

In contrast, biochar addition (regardless of the types used) to the root zone of the HP soils did not enhance either plant yield or P uptake, and this was attributed to the adequate P supply for plant growth in this soil, as indicated by an Olsen $\mathrm{P}$ value of $33.3 \mathrm{mg} \mathrm{kg}^{-1}$ and a relatively high yield of $27 \mathrm{t} \mathrm{DM} \mathrm{ha}^{-1} \mathrm{yr}^{-1}$. Usually, an Olsen $\mathrm{P}$ value $>32 \mathrm{mg} \mathrm{kg}^{-1}$ for a soil with high $\mathrm{P}$ retention is considered adequate for pasture growth (Cornforth 1998). Other studies have also shown that applying biochar to either a soil with a high P status or along with $P$ fertilizer has no additive or synergistic agronomic effects (Solaiman et al. 2010).

\subsection{P status and biochar in the hyphal zone affects plant growth and P uptake}

The proliferation of AMF hyphae is particularly vital for plant $\mathrm{P}$ acquisition as phosphate ions have low mobility in the soil and are often poorly accessible to plant roots (Smith and Read 2010). The external mycelium is the active part of AMF where nutrients are captured, transported and delivered to the host plant roots (Smith and Read 2010). The manifested P deficiency in lotus growing in the LP root zone soil $\left(\frac{\omega}{10}\right.$ treatment) was, to a limited extent, mitigated when AMF hyphae had access to the HP hyphal zone soil ( $\frac{\mathrm{LB}}{\mathrm{HO}}$ treatment), as shown by $56 \%$ and $94 \%$ increases in plant yield and P uptake, respectively. Despite these benefits of hyphal $\mathrm{P}$ uptake, it could not raise plant growth to the levels observed when plant roots were grown directly in the HP root zone soils (cf. $\frac{\text { HO }}{\mathrm{LO}}$ $v s \frac{\text { LO }}{\text { HO }}$ treatments), which is in agreement with previous studies (Hedley et al. 2005).

There was no effect when biochar (regardless of type) was added to the root zone of LP soils that had HP soils in their hyphal zone $\frac{\mathrm{LB}}{\mathrm{HO}}$ compared to the untreated pots $\frac{L_{H}}{H O}$. Conversely, biochar added to the $h y$ phal zone of the HP soil did $\frac{\mathrm{LB}}{\mathrm{HB}}$ enhance $\mathrm{P}$ bioavailability and plant growth compared to the corresponding treatment $\frac{\mathrm{LB}}{\mathrm{HO}}$. Particular, there was a profound increase when BP450 biochar was used. Considering the absence of nutrients (such as P) and the lack of any liming capability of this biochar, along with the inability of (i) roots to take up P from the HP soil (as a mesh impeded their penetration) and (ii) $\mathrm{P}$ to diffuse across the tephra layer (both of which were accomplished in the root study container; Shen et al. unpublished), this positive response could only be attributed to the stimulation of hyphal development by BP450 biochar in the hyphal zone of the HP soil. This was supported by the considerable increase in the length of the AM fungal mycelium of the BP450 treated HP soil in the hyphal zone $\frac{\mathrm{LB}}{\mathrm{HB}}$ when compared to the nonamended treatment $\frac{\text { LO }}{H 0}$ and only the LP root zone soil amended with the BP450 (treatment $\frac{\mathrm{LB}}{\mathrm{HO}}$. This could be ascribed to the fact that biochar can act as a physical growth matrix due to its porous nature (Hammer et al. 2014). 


\section{Conclusion}

Plant growth in our experiment was primarily determined by $\mathrm{P}$ bioavailability in the soil of the root zone. When insufficient $\mathrm{P}$ was available for direct root uptake, this could be partly over come through hyphal $\mathrm{P}$ uptake from the hyphal zone if that contained a high $\mathrm{P}$ soil, but plant growth could not be maintained at the same level to that obtained when there was direct root $\mathrm{P}$ uptake from a high $\mathrm{P}$ soil.

Amongst the tested biochars, biochar produced from willow woodchips achieved the best results in terms of plant growth and P uptake in a P deficient soil. This was attributed to its high liming equivalence and provision of additional $\mathrm{P}$ which made it a useful soil amendment in Andosols with low P fertility, by improving $\mathrm{P}$ bioavailability and thus plant productivity. Biochars derived from pine woodchips conferred no advantages through nutrient addition but stimulated AMF abundance and hyphal function and thereby increased $\mathrm{P}$ accessibility and uptake from high-P soil patches rendering an enhanced plant growth. We concluded that biochar addition had little effect when plants were growing in a soil with sufficient P supply, but biochar derived from pine woodchips facilitated mycorrhizal P uptake when plants were dependent on mycorrhizae to meet their $\mathrm{P}$ requirements.

\section{Acknowledgements}

The authors acknowledge financial support for Qinhua Shen from the New Zealand Biochar Research Centre. The authors are also deeply grateful to Dr James Hanly for providing the tephra and for helping with the OVERSEER ${ }^{\circledR}$ nutrient budget analysis and Dr C Matthew for personal communication on Lotus yield and nutrient managements. We are also grateful for the technical support from Mr Ian Furkert, Mr Bob Toes, and Ms Glenys Wallace, and would like to thank
Drs Tao Wang and Roberto Calvelo Pereira for inspiring discussions of the experimental results, and Prof. Surrinder Saggar, Prof. Eduardo Garcia-Rodeja and Associate Prof. Brett Robinson for their proof reading and suggestions.

\section{References}

Blakemore, L.C., Searle, P.L., Daly, B.K. 1987. Methods for chemical analysis of soils. Soil Bureau, Department of Scientific and Industrial Research, Lower Hutt, New Zealand.

Bolan, N.S., Hedley, M.J. 2003. Role of carbon, nitrogen, and sulfur cycles in soil acidification. In: Rengel, Z (ed.), Handbook of soil acidity, Austrilia, 29-56.

Bolan, N.S., Naidu, R., Syers, J.K., Tillman, R. 1999. Surface charge and solute interactions in soils. Advances in Agronomy. 67, 87-140.

Camps Arbestain, M., Amonette, J.E., Singh, B., Wang, T., Schmidt, H.P. 2015. A biochar classification system and associated test methods. In: Lehmann J and Joseph S (Eds.), Biochar for Environmental Management: Science, Technology and Implementation: 165-193.

Cordell, D., Drangert, J-O., White, S. 2009. The story of phosphorus: Global food security and food for thought. Global Environ Change. 19, 292-305.

Cornforth, I. 1998. Practical Soil Management. Lincoln University Press with Whitireia Publishing and Daphne Brasell Associates Ltd.

Curaqueo, G., Meier, S., Khan, N., Cea, M., Navia, R. 2014. Use of biochar on two volcanic soils: effects on soil properties and barley yield. J. Soil Sci. and Plant Nutr. 14, 4, 911-924.

Dahlgren, R.A., Saigusa, M., Ugolini, F.C. 2004. The Nature, Properties and Management of Volcanic Soils. Advances in Agronomy. 82, 113-182. 
Fieldes, M., Perrott, K.W. 1966. The nature of allophane in soils: Part 3- Rapid field and laboratory test for allophane. New Zealand Journal Science. 9, 623-629.

Goldberg, S., Sposito, G. 1985. On the mechanism of specific phosphate adsorption by hydroxylated mineral surfaces: A review. Commun Soil Sci. Plant Anal. 16, 801-821.

Hammer, E.C., Balogh-Brunstad, Z., Jakobsen, I., Olsson, P.A., Stipp, S.L.S., Rillig, M.C. 2014. A mycorrhizal fungus grows on biochar and captures phosphorus from its surfaces. Soil Biol. Biochem. 77, 252-260.

Haynes, R. 1982. Effects of liming on phosphate availability in acid soils. Plant Soil. 68, 289-308.

Hedley, M., McLaughlin, M., Sims, J., Sharpley, A. 2005. Reactions of phosphate fertilizers and byproducts in soils. Phosphorus: agriculture and the environment, 181-252.

Herath, H.M.S.K., Camps-Arbestain, M., Hedley, M. 2013. Effect of biochar on soil physical properties in two contrasting soils: An Alfisol and an Andisol. Geoderma. 209-210, 188-197.

IBI. 2012. Standardized product definition and product testing guidelines for biochar that is used in soil. International Biochar Initiative.

IUSS Working Group W. 2006. World reference base for soil resources. World Soil Resour Rep. 103.

Lehmann, J., Gaunt, J., Rondon, M. 2006. Bio-char sequestration in terrestrial ecosystems : A review. Mitig Adapt Strateg Glob Change. 11, 395-419.

Mia, S., van Groenigen, J.W., van de Voorde, T.F.J., Oram, N.J., Bezemer, T.M., Mommer, L., Jeffery, S. 2014. Biochar application rate affects biological nitrogen fixation in red clover conditional on potassium availability. Agric. Ecosyst. Environ. 191, 83-91.
Mizota, C., Van Reeuwijk, L. 1989. Clay mineralogy and chemistry of soils formed in volcanic material in diverse climatic regions. ISM Monograph.

Olsen, S.R., Cole, C.V., Watanabe, F.S. 1954. Estimation of available phosphorus in soils by extraction with sodium bicarbonate. Circular / United States Department of Agriculture; no. 939. USDA, Washington.

Parfitt, R. 1989. Phosphate reactions with natural allophane, ferrihydrite and goethite. J. Soil Sci. 40, 359-369.

Perrott, K., Sarathchandra, S. 1987. Nutrient and organic matter levels in a range of New Zealand soils under established pasture. N. Z. J. Agric. Res. 30, 249-259.

Rayment, G., Higginson, F.R. 1992. Australian laboratory handbook of soil and water chemical methods. Inkata Press Pty Ltd.

Saggar, S., Hedley, M.J., White, R.E. 1990. A simplified resin membrane technique for extracting phosphorus from soils. Nutr. Cycl. Agroecosyst. 24, 173-180.

Saunders, W. 1959. Effect of phosphate topdressing on a soil from andesitic volcanic ash: Phosphate retention and pH. N. Z. J. Agric. Res. 2, 659-665.

Smith, S.E., Read, D.J. 2010. Mycorrhizal symbiosis. Access Online via Elsevier.

Solaiman, Z.M., Blackwell, P., Abbott, L.K., Storer P. 2010. Direct and residual effect of biochar application on mycorrhizal root colonisation, growth and nutrition of wheat. Aust. J. Soil Res. 48, 546-554.

Shen, Q., Kirschbaum, M.U.F., Hedley, M.J., CampsArbestain, M. 2016.Testing an alternative method for estimating the length of fungal hyphae using photomicrography and image processing. PLoS ONE (In Press) 
Suckling, F.E.T. 1960. Productivity of pasture species on Hill Country. N. Z. J. Agric. Res. 3, 579-591.

Trolove, S., Hedley, M., Caradus, J., Mackay, A. 1996. Uptake of phosphorus from different sources by Lotus Pedunculatus and three genotypes of Trifolium Repens .1. Plant yield and phosphate efficiency. Soil Research. 34, 1015-1026.

Varela Milla, O., Rivera, E.B., Huang, W.J., Chien, C., Wang, Y.M. 2013. Agronomic properties and characterization of rice husk and wood biochars and their effect on the growth of water spinach in a field test. J. Soil Sci. and Plant Nutr, 2013, 13 (2), 251-266.

Vanek, S., Lehmann, J. 2014. Phosphorus availability to beans via interactions between mycorrhizas and biochar. Plant Soil, 1-19.

Wang, C., Anderson, C., Suárez-Abelenda, M., Wang, T., Camps-Arbestain, M., Ahmad, R., Herath, H.M.S.K. 2015. The chemical composition of native organic matter influences the response of bacterial community to input of biochar and fresh plant material. Plant Soil. 1-18.
Wang, T., Camps-Arbestain, M., Hedley, M. 2013. The fate of phosphorus of ash-rich biochars in a soil-plant system. Plant Soil, 1-14.

Wang T., Camps Arbestain, M., Hedley, M., Bishop, P. 2012a. Predicting phosphorus bioavailability from high-ash biochars. Plant Soil. 357, 173-187.

Wang, T., Camps Arbestain, M., Hedley, M., Bishop, P. 2012b. Chemical and bioassay characterisation of nitrogen availability in biochar produced from dairy manure and biosolids. Org. Geochem. 51, $45-54$.

Warnock, D.D., Lehmann, J., Kuyper, T.W., Rillig, M.C. 2007. Mycorrhizal responses to biochar in soil - concepts and mechanisms. Plant Soil. 300, 9-20.

Yuan, J.H., Xu, R.K. 2011. The amelioration effects of low temperature biochar generated from nine crop residues on an acidic Ultisol. Soil Use Manage. 27, 110-115. 